\title{
ANALISIS KELAYAKAN USAHA KERIPIK KENTANG PADA UD. VIGOR REJOSO KECAMATAN JUNREJO KOTA BATU MALANG
}

\author{
Ruswaji \\ Fakultas Ekonomi, Program Studi Manajemen Universitas Islam Lamongan \\ ruswaji1965@gmail.com \\ Zakky Rachmantha \\ Fakultas Ekonomi, Program Studi Manajemen Universitas Islam Lamongan \\ mantha_84@yahoo.com
}

\begin{abstract}
ABSTRAK
Penelitian ini dilaksanakan pada UD. Vigor Rejoso Kecamatan Junrejo Kota Batu Malang sebagai salah satu kelompok usaha Agroindustri keripik kentang binaan Pusat Layanan Usaha Terpadu (PLUT) Kota Batu Malang. Penelitian ini bertujuan untuk menganalisis Kelayakan usaha keripik kentang pada UD. Vigor Rejoso Kecamatan Junrejo Kota Batu Malang. Metode analisis data yang digunakan dalam penelitian ini adalah dengan menggunakan Rumus analisis biaya dan keuntungan. Sementara untuk menghitung Kelayakan Usaha, rumus yang digunakan adalah, Revenue Cost $(R / C)$, Benefit Cost Ratio $(B / C)$, dan Return On Investment (ROI). Hasil penelitian menunjukkan bahwa Rata-rata penerimaan pada kelompok usaha keripik kentang binaan PLUT Kota Batu Malang adalah Rp. 459.000.000,00/ bulan dengan biaya produksi yang dikeluarkan sebesar Rp. 279.275.000,00/ bulan. Biaya produksi tersebut terdiri dari biaya tetap sebesar $R p$. 55.855.000,00 dan biaya variabel sebesar Rp. 233.420.000,00/ bulan. Dari hasil analisa data, didapatkan bahwa keuntungan yang diperoleh pada agroindustri keripik kentang UD. Vigor sebesar Rp. 179.725.000,00/ bulan. Berdasarkan perhitungan kelayakan usaha $(R / C)$ Ratio yaitu perbandingan antara penerimaan dengan total biaya diperoleh nilai $(R / C)$ Ratio 1,64 atau 1,64 > 1. (B/C) Ratio yaitu perbandingan keuntungan dengan total biaya produksi yang lebih besar dari nol yaitu memiliki angka perbandingan 0,64 atau 0,64 > 0. Berdasarkan perbandingan laba dan modal produksi diperoleh nilai ROI sebesar 64\%. Maka dapat disimpulkan bahwa usaha agroindustri UD. Vigor Rejoso Kecamatan Junrejo Kota Batu Malang dapat dikatakan menguntungkan dan layak dijalankan.
\end{abstract}

Kata kunci : Analisa Usaha, Keuntungan, Kelayakan Usaha dan Usaha Keripik.

\section{PENDAHULUAN}

Agroindustri merupakan bisnis untuk meningkatkan efisiensi sektor pertanian hingga menjadi kegiatan yang sangat produktif melalui proses modernisasi pertanian. Modernisasi di sektor industri dalam skala nasional dapat meningkatkan penerimaan nilai tambah sehingga pendapatan ekspor akan lebih besar (Saragih, 2008). Pada dasarnya Bisnis agroindustri dihadapkan pada persaingan yang lebih ketat 
sehingga harus mampu menghasilkan produk atau jasa yang memiliki daya saing tinggi dalam bisnis memenangkan pangsa pasar, sekaligus menghindari market.

Salah satu usaha kecil yang memiliki prospek sangat potensial untuk dikembangkan di Kota Batu Malang adalah usaha pembuatan keripik kentang. Berdasarkan hasil penelitian potensi ekonomi dari usaha kecil sangat bergantung kepada nilai pengembangan bisnis yang dilakukan. usaha kecil pada sektor industri usaha sebagian besar merupakan industri rumah tangga. Hingga saat ini usaha kecil terutama usaha keripik semakin menjamur. Walaupun besarnya investasi pada industri rumah tangga relatif kecil tetapi cukup banyak menyerap tenaga kerja dan menambah pendapatan masyarakat. Berdasarkan kemampuan industri rumah tangga ini maka pengembangan industri rumah tangga perlu terus dilakukan.

Usaha keripik merupakan salah satu makanan ringan yang bersumber dari bahan baku kentang, pilihan yang telah diolah secara tradisional untuk dapat langsung di konsumsi. Proses penggorengan Keripik ini dilakukan dengan cara memilah-milah kentang yang telah diiris-iris dan selanjutnya adalah menggoreng keripik untuk dapat dikonsumsi, proses yang dilakukan seperti halnya menggoreng keripik pada umumnya.

Kota Batu Malang merupakan salah satu daerah yang banyak terdapat kegiatan agribisnis, salah satunya adalah usaha keripik, diantaranya, keripik kentang, keripik ubi, keripik apel dan keripik lain-lain yang bergerak di agribisnis yang berskala industri rumah tangga atau home industri. Usaha keripik kentang yang merupakan industri rumah tangga tersebar hampir seluruh Kecamatan di Kota Batu, di antaranya Kecamatan Junrejo, Kecamatan Batu dan Kecamatan Bumiaji.

UD. Vigor adalah salah satu usaha produksi keripik di Rejoso Kecamatan Junrejo yang melakukan produksi khusus keripik kentang semenjak tahun 2002. UD. Vigor merupakan usaha keluarga yang dirintis dengan tujuan mampu memproduksi keripik di seluruh Kota Batu Malang. Usaha tersebut dipasarkan melalui penitipan ke kioskios di Kota Batu, Kota Malang dan Kabupaten Malang maupun diluar Kabupaten, serta menunggu pesanan.

Setiap bisnis memerlukan pemahaman layak atau tidak layak usaha tersebut untuk di bangun. Dalam penelitian ini studi kelayakan bisnis merupakan suatu metode atau cara yang terdiri dari berbagai aspek penilaian untuk mengetahui apakah suatu usaha yang akan dikerjakan layak atau tidak. Sehingga dapat dikatakan juga suatu alat peramalan yang sangat mumpuni untuk mengetahui kemungkinan-kemungkinan yang akan terjadi, serta dapat segera mengambil keputusan atas hasil yang diperoleh yakni menerima atau menolak usaha tersebut.

Studi kelayakan bisnis dilakukan untuk melihat sejauhmana tingkat kelayakan usaha keripik kentang UD. Vigor Rejoso Kecamatan Junrejo Kota 
Batu mengenai sejauh mana pemasaran dari produk yang dihasilkan dapat mendukung perkembangan usaha yang akan dilaksanakan. Berdasarkan permasalahan di atas, peneliti tertarik untuk melakukan suatu penelitian mengenai "Analisis Kelayakan Usaha Keripik Kentang pada UD. Vigor Rejoso Kecamatan Junrejo Kota Batu Malang”.

\subsection{Tujuan Penelitian}

Penelitian ini bertujuan untuk menganalisis kelayakan usaha keripik kentang di UD. Vigor Rejoso Kecamatan Junrejo Kota Batu Malang sebagai salah satu kelompok usaha Agroindustri binaan Pusat Layanan Usaha Terpadu (PLUT) Kota Batu Malang Jawa Timur.

\section{METODE PENELITIAN}

Penelitian dilaksanakan di UD. Vigor Rejoso Kecamatan Junrejo sebagai salah satu kelompok usaha Agroindustri keripik kentang binaan Pusat Layanan Usaha Terpadu (PLUT) kota Batu Malang, pemilihan lokasi penelitian ditentukan dengan metode deskriptif. Menurut Arikunto (2007) purposive adalah suatu teknik penentuan lokasi penelitian secara sengaja berdasarkan atas pertimbangan-pertimbangan tertentu. Penelitian telah dilaksanakan pada bulan Juli 2018.

\subsection{Jenis dan Sumber Data}

Data yang dikumpulkan pada penelitian ini meliputi data primer dan data sekunder, dengan jenis data sebagai berikut :

1. Data primer, yaitu data yang diperoleh langsung dari lapangan melalui wawancara dengan responden secara langsung dan pengamatan (observasi) langsung di lapangan.

2. Data sekunder, yaitu data yang diperoleh dari instansi-instansi terkait dengan masalah dan obyek yang diteliti.

\subsection{Analisis Data}

Metode analisis data yang digunakan adalah perhitungan pendapatan, dan perhitungan studi pengembangan bisnis (Soekartawi: 2009).

\section{Pendapatan}

Dimana:

$\mathrm{TR}=$ Total pendapatan dari bisnis

keripik (Rupiah)

$\mathrm{Q} \quad=$ Total produk yang terjual dari bisnis keripik $(\mathrm{Kg})$

$\mathrm{P}=$ Harga produk dari bisnis

keripik (Rupiah)

\section{Keuntungan}

Pengklasifikasian rumus keuntungan berdasarkan sifatnya dirumuskan sebagai berikut:

$\Pi=\mathrm{TR}-\mathrm{TC}$

Keterangan:

$\Pi=$ Keuntungan

$T R=$ Total Revenue/penerimaan

$\mathrm{TC}=$ Total Cost adalah biaya total.

1. Analisis Kelayakan bisnis (R/C Ratio) Untuk mengetahui layak tidaknya suatu bisnis, digunakan rumus $\mathrm{R} / \mathrm{C}$ ratio yaitu dengan cara membandingkan tingkat pendapatan yang diperoleh dengan modal yang harus dikeluarkan. Layak tidaknya bisnis, biasanya dihitung dengan standar $\mathrm{R} / \mathrm{C}$ ration $>1$ 
Maka analisis kelayakan dari $\mathrm{R} / \mathrm{C}$ ratio adalah :

b) $\mathrm{R} / \mathrm{C}=1=\mathrm{BEP}$

c) $\mathrm{R} / \mathrm{C}<1$ = Tidak Layak / Rugi

2. $\mathrm{B} / \mathrm{C}$

B/C Ratio (Benefit Cost Ratio) adalah ukuran perbandingan antara pendapatan (Benefit = B) dengan Total Biaya produksi $($ Cost $=\mathrm{C})$. Dalam batasan besaran nilai $\mathrm{B} / \mathrm{C}$ dapat diketahui apakah suatu bisnis menguntungkan atau tidak menguntungkan. Rumus:

$\mathrm{B} / \mathrm{C}$ ratio = Jumlah Keuntungan $(\mathrm{B}) /$ Total Biaya Produksi (TC) Jika B/C ratio $>0$, bisnis layak dilaksanakan Jika B/C ratio $<0$, bisnis tidak layak atau merugi

3. ROI

ROI bisa juga diartikan sebagai rasio keuntungan bersih terhadap biaya. Rumus menghitung ROI adalah sebagai berikut:

\section{Keuntungan \\ ROI $=\longrightarrow \times 100 \%$ \\ Total Biaya}

a) $\quad$ R/C $>1=$ Layak / Untung

\section{HASIL PENELITIAN}

\subsection{Analisis Biaya}

Biaya tetap agroindustri keripik Mawar. Biaya tetap (fixed cost) adalah biaya yang dikeluarkan oleh industri keripik Vigor yang penggunaannya tidak habis dalam satu masa produksi. Besar kecilnya biaya produksi tersebut tidak dipengaruhi oleh banyaknya produksi yang dihasilkan oleh industri keripik Vigor. Pada industri keripik Vigor yang termasuk biaya tetap adalah biaya penyusutan peralatan, biaya bangunan dan biaya perawatan.

$$
\text { Adapun komponen biaya }
$$
penyusutan peralatan pada industri keripik kentang Vigor dapat dilihat pada Tabel 1 dibawah ini

Tabel 1. Biaya Penyusutan Peralatan Pada Industri Keripik Vigor

\begin{tabular}{|c|c|c|c|c|c|c|}
\hline No & $\begin{array}{c}\text { Uraian } \\
\text { Biaya }\end{array}$ & $\begin{array}{c}\text { Jumlah } \\
\text { ( Unit) }\end{array}$ & $\begin{array}{c}\text { Umur } \\
\text { Ekonomis } \\
\text { ( Tahun ) }\end{array}$ & $\begin{array}{l}\text { Harga } \\
\text { ( Rp/ unit ) }\end{array}$ & $\begin{array}{c}\text { Jumlah } \\
\text { (Rp) }\end{array}$ & $\begin{array}{c}\text { Nilai } \\
\text { Penyusutan } \\
\text { ( Rp/ bulan) }\end{array}$ \\
\hline 1 & Bangunan & 1 & 12 & 25.000 .000 & 25.000 .000 & 173.611 \\
\hline 2 & Mesin Rajang & 2 & 5 & 3.000 .000 & 6.000 .000 & 100.000 \\
\hline 3 & Ember Besar & 5 & 2 & 120.000 & 600.000 & 25.000 \\
\hline 4 & Kuali & 5 & 4 & 400.000 & 2.000 .000 & 41.667 \\
\hline 5 & Mesin Air & 1 & 4 & 400.000 & 400.000 & 8.333 \\
\hline 6 & Keranjang & 4 & 3 & 40.000 & 160.000 & 4.444 \\
\hline 7 & Centong & 5 & 3 & 50.000 & 250.000 & 6.944 \\
\hline 8 & Mesin Press & 1 & 10 & 3.000 .000 & 300.000 & 25.000 \\
\hline \multirow[t]{2}{*}{9} & Tungku & 5 & 5 & 600.000 & 3.000 .000 & 50.000 \\
\hline & Penggorengan & & & & & \\
\hline 10 & Pisau & 6 & 2 & 30.000 & 180.000 & 7.500 \\
\hline 11 & Timbangan & 4 & 4 & 120.000 & 480.000 & 10.000 \\
\hline \multirow[t]{2}{*}{12} & Becak & 1 & 12 & 8.000 .000 & 8.000 .000 & 55.555 \\
\hline & Total & & & 40.760 .000 & 46.370 .000 & $\overline{508.054}$ \\
\hline
\end{tabular}

Sumber : Data primer diolah, Tahun 2018

Berdasarkan Tabel 1 diatas dapat dilihat penggunaan biaya tetap yang harus dikeluarkan oleh agroindustri UD. Vigor berupa penyusutan sebesar
Rp. 508.054,-per bulannya. Nilai penyusutan diperoleh dari jumlah unit dikali dengan harga dibagikan dengan umur ekonomis, untuk mendapatkan 
perbulannya dibagikan dengan 12 bulan. keripik Vigor dapat dilihat pada tabel 2 Adapun total biaya tetap agroindustri dibawah ini.

Tabel 2. Total Biaya Tetap Industri Keripik Kentang Per Bulan

\begin{tabular}{|c|l|c|}
\hline No. & \multicolumn{1}{|c|}{ Uraian } & $\begin{array}{c}\text { Jumlah } \\
\text { (Rp/bulan) }\end{array}$ \\
\hline 1 & Biaya Penyusutan Peralatan & 508.054 \\
\hline 2 & Biaya Perawatan & 250.000 \\
\hline 3 & Biaya Gaji Direktur \& Karyawan Tetap & 55.000 .000 \\
\hline & Total Biaya & $\mathbf{5 5 . 8 5 5 . 0 0 0}$ \\
\hline
\end{tabular}

Sumber : Data primer diolah, Tahun 2018

Berdasarkan tabel 2 diatas total biaya tetap adalah sebesar Rp. 55.855.000/ bulan. Komponen biaya lainnya yang termasuk dalam biaya tetap adalah biaya non produksi yaitu biaya perawatan kendaraan operasional. Biaya perawatan merupakan biaya yang dikeluarkan hanya untuk perawatan pada kendaraan operasional. Biaya perawatan terhadap operasional dilakukan dengan periode waktu satu bulan sekali yaitu sebesar Rp. 250.000/ untuk service sepeda motor dan ganti oli. Dan biaya Gaji Manajer dan Karyawan Tetap sebesar Rp 55.000.000,-.

\subsection{Biaya Variabel Agroindustri Keripik}

Biaya variabel adalah biaya yang besarnya sangat tergantung pada jumlah produksi. Biaya variabel pada industry keripik Vigor meliputi biaya bahan baku biaya kemasan, biaya bahan bakar, biaya tenaga kerja, biaya tranportasi, dan biaya lain-lain

\subsection{Biaya bahan baku}

Biaya bahan baku merupakan biaya yang digunakan untuk membeli bahan baku untuk pembuatan keripik. Jenis bahan baku yang digunakan pada industri keripik Vigor terbagi menjadi 2 yaitu bahan baku utama dan bahan baku penunjang. Bahan baku utama pembuatan keripik adalah kentang. Sedangkan bahan baku penunjang adalah garam, minyak goreng, bawang merah, bawang putih, dan mentega.

Tabel 3. Total biaya bahan baku industri keripik Vigor Per Bulan.

\begin{tabular}{|c|l|r|r|r|r|}
\hline No & Uraian & $\begin{array}{c}\text { Jumlah } \\
\text { Produksi } \\
\text { (Hari) }\end{array}$ & $\begin{array}{c}\text { Harga } \\
\text { Rp / } \\
\text { Satuan }\end{array}$ & $\begin{array}{c}\text { Nilai } \\
\text { Rp / Satuan }\end{array}$ & $\begin{array}{c}\text { Jumlah } \\
\text { Rp/Satuan }\end{array}$ \\
\hline 1 & Kentang & $1.125 \mathrm{~kg}$ & 4.000 & 4.500 .000 & 135.000 .000 \\
\hline 2 & Garam & $10 \mathrm{~kg}$ & 6.000 & 60.000 & 1.800 .000 \\
\hline 3 & Minyak Goreng & $10 \mathrm{~kg}$ & 25.000 & 250.000 & 7.500 .000 \\
\hline 4 & Bawang Merah & $5 \mathrm{~kg}$ & 15.000 & 75.000 & 2.250 .000 \\
\hline
\end{tabular}




\begin{tabular}{|c|c|c|c|c|c|}
\hline No & Uraian & $\begin{array}{c}\text { Jumlah } \\
\text { Produksi } \\
\text { (Hari) }\end{array}$ & $\begin{array}{c}\text { Harga } \\
\text { Rp/ } \\
\text { Satuan }\end{array}$ & $\begin{array}{c}\text { Nilai } \\
\text { Rp / Satuan }\end{array}$ & $\begin{array}{c}\text { Jumlah } \\
\text { Rp/Satuan }\end{array}$ \\
\hline 5 & Bawah Putih & $5 \mathrm{~kg}$ & 25.000 & 125.000 & 3.750 .000 \\
\hline 6 & Mentega & $5 \mathrm{~kg}$ & 8.000 & 40.000 & 1.200 .000 \\
\hline \multicolumn{2}{|r|}{ Total } & & $\mathbf{1 5 1 . 5 0 0 . 0 0 0}$ \\
\hline
\end{tabular}

Sumber: Data primer diolah, Tahun 2018

Berdasarkan tabel 3 menunjukkan bahwa total biaya bahan baku adalah sebesar Rp. 151.500.000/ bulan, meliputi harga kentang Rp. 135.000.000/bulan, garam 9Rp. $1.800 .000 /$ bulan, minyak goreng Rp. 7.500.000/ bulan, bawang merah Rp. 2.250.000/ bulan, bawang putih Rp. 3.750.000/bulan, dan mentega Rp. $1.200 .000 /$ bulan.

\subsection{Biaya Kemasan}

Biaya kemasan merupakan biaya yang dikeluarkan untuk membeli kemasan keripik berupa plastik yang sudah diberi lebel. Kemasan keripik yang dibeli diperoleh dengan pemesanan terlebih dahulu dari Malang. Adapun rincian biaya kemasan yang dikeluarkan industri keripik kentang pada UD. Vigor Kecamatan Junrejo Kota Batu Malang dalam satu bulan produksi dapat dilihat pada tabel 4 berikut ini:

Tabel 4. Total Biaya Kemasan Industri Keripik Vigor Per Bulan

\begin{tabular}{|c|c|c|c|c|c|}
\hline No & Uraian & $\begin{array}{c}\text { Jumlah } \\
\text { (Hari) }\end{array}$ & $\begin{array}{c}\text { Harga } \\
(\mathbf{R} / \\
\text { Satuan })\end{array}$ & $\begin{array}{c}\text { Nilai } \\
(\text { Rp/Satuan) }\end{array}$ & $\begin{array}{c}\text { Jumlah } \\
(\mathbf{R p} / \\
\text { Bulan) }\end{array}$ \\
\hline 1 & Plastik Kemasan Berlebel & $5 \mathrm{~kg}$ & 50.000 & 250.000 & 7.500 .000 \\
\hline 2 & Plastik Besar & $5 \mathrm{~kg}$ & 30.000 & 150.000 & 4.500 .000 \\
\hline \multicolumn{2}{|c|}{ Total } & $\mathbf{7 5 . 0 0 0}$ & $\mathbf{4 0 0 . 0 0 0}$ & $\mathbf{1 2 . 0 0 0 . 0 0 0}$ \\
\hline
\end{tabular}

Sumber: Data primer (diolah), Tahun 2018

Berdasarkan tabel diatas menunjukkan bahwa biaya kemasan untuk plastik kemasan berlebel adalah sebesar Rp. 7.500.000/ bulan. Sedangkan biaya kemasan untuk plastik besar biasa adalah sebesar Rp.4.500.000/ bulan. Dan total biaya kemasan yang harus dikeluarkan oleh industri keripik Vigor sebesar Rp. 12.000.000/ bulan.

\subsection{Biaya Bahan Bakar}

Biaya bahan bakar terdiri dari bahan bakar kayu. Bahan bakar kayu digunakan sebagai bahan bakar untuk proses pengorengan keripik. Jumlah kayu yang digunakan dalam proses produksi adalah sebanyak satu truck untuk 5 hari produksi dengan biaya sebesar Rp.250.000/ truck atau Rp. 1.250.000/ bulan.

\subsection{Biaya Tenaga Kerja}

Adapun penggunaan tenaga kerja pada industri keripik Vigor 30 orang yang terdiri dari tenaga kerja bagian pengupasan, pencetakan, penjemuran, 
penggorengan, dan pengemasan. Tenaga kerja yang ada pada industri tersebut menggunakan sitem upah harian yang Adapun total biaya tenaga kerja adalah sebesar Rp. 2.250.000 / hari dan Rp. 67.500.000/ bulan. Untuk lebih masing-masing tenaga kerja mendapatkan upah yang sama, yaitu $\mathrm{Rp}$. 75.000/ hari.

jelasnya terhadap penggunaan tenaga kerja dapat dilihat pada Tabel 5 berikut ini :

Tabel 5. Penggunaan Tenaga Kerja Pada Industri Keripik Vigor Per Bulan.

\begin{tabular}{clcccr}
\hline No & $\begin{array}{l}\text { Jenis } \\
\text { Kegiatan }\end{array}$ & Jumlah & $\begin{array}{c}\text { Upah } \\
\text { ( hari) }\end{array}$ & $\begin{array}{c}\text { Jumlah }( \\
\text { Rp) }\end{array}$ & $\begin{array}{c}\text { Jumlah } \\
\text { ( Rp/ Bulan ) }\end{array}$ \\
\hline 1 & Pengupasan & 8 & 75.000 & 600.000 & 18.000 .000 \\
2 & Pencetakan & 8 & 75.000 & 600.000 & 18.000 .000 \\
3 & Penjemuran & 4 & 75.000 & 300.000 & 9.000 .000 \\
4 & Penggorengan & 5 & 75.000 & 375.000 & 11.250 .000 \\
5 & Pengemasan & 5 & 75.000 & 375.000 & 11.250 .000 \\
\hline & Total Biaya & $\mathbf{3 0}$ & $\mathbf{3 7 5 . 0 0 0}$ & $\mathbf{2 . 2 5 0 . 0 0 0}$ & $\mathbf{6 7 . 5 0 0 . 0 0 0}$
\end{tabular}

Sumber: Data primer diolah, Tahun 2018

\subsection{Biaya Transportasi}

Biaya transportasi pada usaha keripik adalah biaya untuk pengisian bahan bakar bensin untuk kendaraan becak yang dilakukan sehari sekali $\mathrm{Rp}$. 20.000 per harinya per kali sebulan atau Rp. 600.000/ bulannya. Biaya transportasi digunakan untuk kegiatan penyaluran keripik.

\subsection{Biaya lain-lain}

Komponen biaya lain yang harus dikeluarkan oleh industri keripik Vigor adalah biaya listrik, biaya komunikasi harian. Jumlah biaya penggunaan listrik yang harus dikeluarkan Industri keripik Vigor setiap bulannya adalah Rp. 270.000/ bulan. Dan biaya komunikasi adalah sebesar Rp.300.000/ bulan.

\subsection{Total Biaya Variabel}

Total biaya variabel adalah total biaya tidak tetap yang dikeluarkan oleh UD. Vigor selama satu bulan produksi. Adapun rincian total biaya variabel dalam satu bulan produksi pada UD. Vigor Rejoso Kecamatan Junrejo Kota Batu Malang dapat dilihat pada tabel 6 berikut ini.

Tabel 6. Total Biaya Variabel Industri Keripik Kentang Vigor Per Bulan

\begin{tabular}{|c|c|c|}
\hline No. & Uraian & Jumlah \\
\hline 1 & $\begin{array}{l}\text { Biaya bahan } \\
\text { baku }\end{array}$ & 151.500 .000 \\
\hline 2 & Biaya kemasan & 12.000 .000 \\
\hline 3 & $\begin{array}{c}\text { Biaya bahan } \\
\text { bakar } \\
\sim \text { Biaya bahan } \\
\text { bakar kayu }\end{array}$ & 1.250 .000 \\
\hline 4 & $\begin{array}{l}\text { Biaya tenaga } \\
\text { kerja }\end{array}$ & 67.500 .000 \\
\hline 5 & $\begin{array}{l}\text { Biaya } \\
\text { Transportasi }\end{array}$ & 600.000 \\
\hline 6 & $\begin{array}{l}\text { Biaya Lain- } \\
\text { lain } \\
\sim \text { Biaya listrik } \\
\sim \text { Biaya } \\
\text { komunikasi }\end{array}$ & $\begin{array}{l}270.000 \\
300.000\end{array}$ \\
\hline & Total Biaya & 233.420.000 \\
\hline
\end{tabular}


Tabel 6 menunjukkan bahwa total biaya variabel yang harus dikeluarkan oleh Industri keripik kentang Vigor seiap bulannya adalah sebesar Rp 233.420.000,- dengan variabel tersebesar yang harus

\subsection{Total Biaya Produksi}

Total biaya produksi adalah keseluruhan biaya yang digunakan untuk melakukan proses produksi dikeluarkan adalah untuk biaya bahan baku yaitu sebesar Rp. 151.500.000/ bulan dan biaya variabel terkecil adalah untuk biaya listrik yaitu Rp. 270.000/bulan.

keripik dari awal sampai pemasaran. Adapun Perincian total biaya produksi pada UD. Vigor Rejoso Kecamatan Junrejo Kota Batu Malang dapat dilihat pada tabel 7 berikut ini :

Tabel 7. Total biaya industri keripik kentang

Vigor Per bulan

\begin{tabular}{|r|c|c|}
\hline No. & Penerimaan Biaya & $\begin{array}{c}\text { Jumlah Biaya } \\
\text { (Rp/bln) }\end{array}$ \\
\hline 1 & Total Biaya Tetap & 55.855 .000 \\
\hline 2 & Total Biaya Variabel & 233.420 .000 \\
\hline & Total Biaya & $\mathbf{2 7 9 . 2 7 5 . 0 0 0}$ \\
\hline
\end{tabular}

Sumber : Data primer diolah, Tahun 2018

Analisis penerimaan berfungsi untuk mengukur berhasil tidaknya suatu usaha, menentukan komponen utama pendapatan dan apakah komponen itu masih dapat ditingkatkan atau tidak. Menurut Soekartawi (2009), pendapatan merupakan total nilai produksi dari usaha dalam jangka waktu tertentu dikali dengan harga jual. Rata-rata produksi dan nilai produksi dari usaha keripik dapat dilihat pada tabel 8 berikut.

Tabel 8. Jumlah Penerimaan Industri Keripik Vigor Per Bulan

\begin{tabular}{cccccc}
\hline No & Uraian & $\begin{array}{c}\text { Jumlah } \\
\text { Produksi } \\
(\text { Kg/ Hari) }\end{array}$ & $\begin{array}{c}\text { Harga } \\
(\mathbf{R p} / \text { Kg) }\end{array}$ & $\begin{array}{c}\text { Nilai } \\
\text { Produk } \\
\text { ( Rp/ Hari) }\end{array}$ & $\begin{array}{c}\text { Nilai } \\
\text { Produk } \\
\text { ( Rp/ Bulan })\end{array}$ \\
\hline \multirow{2}{*}{$\begin{array}{l}\text { Keripik } \\
\text { Kentang }\end{array}$} & $180 \mathrm{~kg}$ & 85.000 & 15.300 .000 & 459.000 .000 \\
\hline \multicolumn{2}{c}{ Total } & & & $\mathbf{1 5 . 3 0 0 . 0 0 0}$ & $\mathbf{4 5 9 . 0 0 0 . 0 0 0}$ \\
\hline
\end{tabular}


Tabel 8. Menunjukkan bahwa keripik kentang yang dihasilkan UD. Vigor, keripik kentang dengan harga jual $85.000 / \mathrm{kg}$. Besar pendapatan kotor yang diterima yaitu : Rp. 459.000.000/ bulan. pengeluaran untuk periode tertentu. Rata rata keuntungan pada usaha produksi keripik kentang dapat dilihat pada tabel berikut.

Tabel 9. Keuntungan Industri Kerupuk Vigor Per Bulan

\begin{tabular}{|c|l|c|}
\hline No & \multicolumn{1}{|c|}{ Uraian } & Jumlah ( Rp/ Bulan) \\
\hline 1 & Total Penerimaan & 459.000 .000 \\
\hline 2 & Total Biaya & 279.275 .000 \\
\hline \multicolumn{2}{|c|}{ Keuntungan } & 179.725 .000 \\
\hline
\end{tabular}

Sumber: Data Primer (diolah), Tahun 2018

\subsection{Analisis Keuntungan}

Keuntungan merupakan kegiatan usaha yang mengurangkan beberapa biaya yang dikeluarkan dengan hasil penjualan yang diperoleh. M. Nafarin (2007) mengemukakan bahwa keuntungan adalah perbedaan antara pendapatan dengan keseimbangan biaya-biaya . Berdasarkan tabel diatas dapat dilihat total penerimaan usaha keripik UD. Vigor sebesar Rp. 459.000.000/ bulan, sedangkan total biaya yang dikeluarkan sebanyak Rp. 279.275.000/ bulan. Adapun keuntungan yang diperoleh dari total penerimaan dikurangi dengan total biaya yang dikeluarkan adalah sebesar Rp. 179.725.000/ bulan.

\subsection{Analisis Kelayakan Usaha Revenue/ Cost (R/ C)}

Revenue cost adalah besaran nilai yang menunjukkan perbandingan antara penerimaan usaha dengan total biaya. Perhitungan analisis revenue/cost dapat di lihat sebagai berikut:

$$
\mathrm{R} / \mathrm{C}=\frac{459.000 .000}{279.275,000}
$$

$\mathrm{R} / \mathrm{C}=1,64$

Berdasarkan perbandingan total penerimaan dan total biaya menunjukkan bahwa perhitungan $\mathrm{R} / \mathrm{C}$ rasio pada UD. Vigor yaitu menguntungkan karena nilai $\mathrm{R} / \mathrm{C}$ rasio Rp. 1,64 > 1. Artinya setiap pengeluaran Rp.100,-, memberikan penerimaan sebesar Rp. 164 maka agroindustri UD. Vigor layak untuk diusahakan.

\subsection{Benefit/Cost (B/C) Ratio}

Benefit/Cost $(\mathrm{B} / \mathrm{C})$ ratio adalah analisis bisnis untuk memberikan gambaran kenapa harus memilih atau tidak memilih spesifikasi dari suatu investasi (Keen, 2011). Dalam batasan besaran nilai $\mathrm{B} / \mathrm{C}$ Ratio dapat diketahui apakah suatu usaha menguntungkan atau tidak menguntungkan.

$\begin{aligned} \mathrm{B} / \mathrm{C} & =\frac{179.725 .000}{279.275 .000} \\ \mathrm{~B} / \mathrm{C} & =0,64\end{aligned}$


Artinya setiap biaya produksi yang dikeluarkan sebesar Rp. 100,-, maka akan diperoleh keuntungan sebesar Rp. 64 menunjukkan bahwa Agroindustri Keripik Vigor dapat dikatakan layak (untung) untuk diusahakan. Hal ini dapat dilihat dari perbandingan total penerimaan dengan total biaya produksi yang lebih besar dari nol.

\subsection{On Investment (ROI)}

Return On Investment (ROI) adalah salah satu bentuk dari rasio profitabilitas yang dimaksudkan untuk mengukur kemampuan perusahaan dengan keseluruhan dana yang ditanamkan dalam aktiva yang digunakan untuk operasinya perusahaan untuk menghasilkan keuntungan.

$$
\begin{aligned}
\text { ROI } & =\frac{179.725 .000}{279.275 .000} \times 100 \% \\
\text { ROI } & =0,64 \times 100 \% \\
\text { ROI } & =64 \%
\end{aligned}
$$

Berdasarkan perbandingan laba dan modal produksi diperoleh nilai ROI sebesar 64\%, yang berarti bahwa besarnya keuntungan yang diperoleh dibandingkan investasi (ROI) besarnya keuntungan yang diperoleh dibandingkan dengan investasi yang ditanamkan adalah baik, artinya setiap modal sebesar Rp. 100, diperoleh keuntungan sebesar Rp. 64.

\section{KESIMPULAN}

Berdasarkan hasil penelitian pada UD. Vigor penulis dapat menyimpulkan bahwa usaha agroindustri keripik kentang UD. Vigor menguntungkan dan layak untuk diusahakan karena memiliki R/C diperoleh nilai sebesar 1,64 sedangkan B/C 0,64 dan ROI diperoleh nilai sebesar $64 \%$.

\section{DAFTAR PUSTAKA}

Arikunto, S. 2007. Prosedur Penelitian; Suatu Pendekatan Praktik. Jakarta: Rineka Cipta.

Baridwan , Zaky, 2007, Sistem Akuntansi Penyusunan Prosedur Dan Metode.Yogyakarta: YKPN.

Husein Umar, 2009, Seni Desain Penelitian Bisnis No 1, PT Raja Grafindo Persada Jakarta.

Mustaniroh. 2011. Kelayakan Teknik Dan Finansial Pengembangan Bisnis Keripik Waluh Di Kabupaten Bogor. Institut Pertanian Bogor.

Nafarin,M. 2007. Studi Kelayakan Bisnis. Jakarta : Salemba Empat.

Purwoko dan Yandra Arkeman, 2013. Kelayakan Industri Kerupuk Jamur Tiram Di

Ridwan. 2007. Pengantar

$$
\text { Statistik Penelitian }
$$

Pendidikan Sosial Ekonomi Komunikasi Dan Bisnis. Bandung. Alfabeta.

Saragih B. 2008 Kumpulan Pemikiran Agribisnis Berbasis Peternakan. USESE Fondation dan Pusat Studi Pembangunan. IPB Bogor.

Soeharjo, 2008. Sendi Sendi Pokok Usaha Tani. Departemen Ilmu Sosial Ekonomi. Fakultas Pertanian, IPB. Bogor.

Soekartawi. 2009. Agribisnis. Teori dan Aplikasinya. Rajawali Pers Universitas Brawijaya. Jakarta. 
Soekartawi, 2006, Analisis Usaha Tani, UI-Press, Jakarta.

S.Munawir,2007. Pengembangan usaha. Liberty, Yogyakarta.

Soni Supriatna. 2012. "Analisis Strategi Pengembangan Bisnis Kopi Luwak . Bandung.

S.R.Soemarso. 2009. Akutansi Suatu Pengantar. Edisi Kelima. Jakarta : Penerbit Salemba Empat.

Sugiyono. 2007. "Metode Penelitian Kuantitatif Kualitatif dan R\&D". Bandung: Alfabeta.

Suharso dan Ana Retnoningsih. 2005. Kamus Besar Bahasa Indonesia Edisi Lux. Semarang:Widya Karya.

Sumiyati. 2013. Analisis Kelayakan keripik Pisang Di Kecamatan Gorontalo.

Supranto, 2001. Statistik Teori dan Aplikasi, Cetakan Kedua, Jakarta: Penerbit. Erlangga.

Syafril. 2010. Ilmu Pengetahuan Sosial Ekonomi. Jakarta: Bumi aksara. 